\title{
ROBÓTICA EDUCACIONAL: UM RECURSO PARA ABORDAR OS CONCEITOS DE MOVIMENTO E VELOCIDADE NO ENSINO FUNDAMENTAL
}

\author{
Rodrigo Biehl (IFSUL) - rodrigobiehl@ifsul.edu.br \\ Silvana Neumann Martins (UNIVATES) - smartins@univates.br \\ Sônia Elisa Marchi Gonzatti (UNIVATES) - soniag@univates.br
}

Resumo. Este artigo apresenta resultados decorrentes de atividades oriundas de uma investigação intitulada "Robótica Educacional: um recurso para introduzir o estudo da Física no ensino fundamental”. O problema investigado foi como a Robótica Educacional pode contribuir para introduzir conceitos de Física no nono ano do Ensino Fundamental, em uma escola pública. O cenário deste estudo ocorreu em uma escola da rede municipal na cidade de Lajeado, Rio Grande do Sul, tendo, como participantes vinte estudantes. A pesquisa é de natureza qualitativa e para levantamento dos dados, foram utilizadas anotações do pesquisador, questionários, fotos, filmagens e relatórios elaborados pelos alunos. Os dados apontaram que as atividades de Robótica proporcionaram um ambiente de colaboração, construção e investigação. Também foi possível verificar a evolução das concepções dos alunos sobre os conceitos de movimento e velocidade após a participação na intervenção pedagógica realizada.

Palavras chave: Robótica Educacional; Ensino de Física; Ensino Fundamental.

\section{EDUCATIONAL ROBOTICS: A RESOURCE TO APPROACH THE CONCEPTS OF MOVEMENT AND SPEED IN ELEMENTARY SCHOOL}

\begin{abstract}
This article presents results from activities from an investigation entitled "Educational Robotics: a resource to introduce the study of physics in elementary school". The problem investigated was how Educational Robotics can contribute to introduce concepts of Physics in the ninth year of Elementary School in a public school. The scenario of this study occurred in a school of the municipal network in the city of Lajeado, Rio Grande do Sul, having, as participants, twenty students. The research is qualitative in nature and for data collection, researchers' annotations, questionnaires, photos, filming and reports prepared by the students were used. The data showed that Robotics activities provided an environment of collaboration, construction and research. It was also possible to verify the evolution of students' conceptions about the concepts of movement and speed after participation in the pedagogical intervention.
\end{abstract}

Keywords: Educational Robotics; Physics Teaching; Elementary School.

\section{INTRODUÇÂO}

Ensinar os conceitos das Ciências no Ensino Fundamental tem sido um desafio para professores das escolas no Brasil. A Base Nacional Comum Curricular do Ensino Fundamental (BRASIL, 2017), incentiva uma abordagem pedagógica dinâmica em que as diversas áreas das ciências se complementem, sejam contextualizadas e proporcionem aos alunos coletar e processar informações, avaliar situações e tomar decisões de forma crítica e autônoma. Ainda estabelece que é função da escola e do professor promover o 
debate, a investigação e o questionamento, visando ao entendimento da ciência como construção histórica e saber prático, superando as limitações do ensino passivo, fundamentado na memorização de conceitos e fórmulas.

No entanto, percebe-se que esses pressupostos nem sempre são colocados em prática. Os temas relacionados à Física, pertinentes ao Ensino Fundamental, normalmente são abordados de maneira superficial e descontextualizada. Nas escolas, em geral, a introdução ao ensino de Física normalmente ocorre no ciclo final do Ensino Fundamental, sendo direcionado pelo livro didático.

Em sua pesquisa, Rosati (2015) constata que os livros didáticos para a disciplina de Ciências do $9^{\circ}$ ano, às vezes, exigem um nível elevado de habilidades com formalismos matemáticos, o que dificulta o acompanhamento pelos alunos. Além disso, o conteúdo frequentemente é apresentado em forma de tópicos e as atividades propostas restringemse, em geral, a responder questões e resolver problemas, que acabam sendo meras repetições de definições ou aplicação automática de fórmulas, que, em sua grande maioria, não avaliam o domínio e as dificuldades conceituais do aluno.

Neste sentido, as atividades de robótica podem ser uma alternativa para superar esta realidade, proporcionando aos estudantes meios para correlacionar os conhecimentos desenvolvidos na sala de aula com uma situação prática. As atividades de Robótica, segundo Papert (1994), permitem que os alunos testem diferentes possibilidades para a resolução de um problema promovendo o contato com conceitos e hipóteses para a produção do conhecimento.

Ao encontro das ideias de Papert, Fornaza (2016) relata em seu estudo que por meio das atividades de robótica os estudantes interagem, trocam ideias e testam hipóteses em busca da solução aos desafios propostos. Com isso, se socializam, desenvolvem o trabalho cooperativo e exercem sua criatividade e autonomia, princípios que podem favorecer a aprendizagem e tornar o estudo da Física mais atrativo e dinâmico.

Por meio da montagem e programação de robôs, é possível estimular o interesse dos alunos, ajudando-os a perceber a importância do estudo da Física e sua aplicação para explicar e compreender fenômenos e eventos do cotidiano, bem como das diversas profissões nas áreas tecnológicas, nas quais muitos têm o desejo de atuar. Utilizando a tecnologia presente nos dispositivos robóticos, pode-se incentivar a pesquisa e a descoberta. Cabe aqui, salientar que a tecnologia desperta a curiosidade sobre o funcionamento dos diversos componentes que fazem parte da construção de um robô e suas relações com o estudo da Física.

Partindo deste contexto, realizou-se uma intervenção pedagógica com uma turma de $9^{\circ}$ ano do Ensino Fundamental de uma escola pública do município de Lajeado, Rio Grande do Sul, tendo como objetivo averiguar como a Robótica Educacional pode contribuir para introduzir conceitos da Física na disciplina de Ciências. A intervenção foi dividida em dez aulas, com a participação de vinte alunos. Neste artigo apresentam-se resultados decorrentes de atividades relacionadas ao estudo do conceito de movimento e velocidade.

Para desenvolver esta proposta, buscou-se aplicar os pressupostos das Metodologias Ativas (BERBEL, 2011) e das práticas experimentais investigativas (AZEVEDO, 2004). Assim, as atividades e experimentos não foram realizados com o propósito de apenas comprovar uma teoria ou observar a aplicação de um conceito. Outros objetivos foram considerados importantes, como por exemplo, a mobilização dos 
alunos para a solução de um problema e a busca por uma metodologia para chegar à solução, bem como às implicações e às conclusões provenientes desse estudo.

\section{EMBASAMENTO TEÓRICO}

De acordo com Menezes e Santos (2002), os termos Robótica Educacional ou Robótica Pedagógica referem-se a ambientes de aprendizagem que reúnem materiais de sucata ou kits de montagem, constituídos por diversas peças, motores e sensores controláveis por computadores e softwares que permitem programar o funcionamento dos modelos montados. Em ambientes de Robótica Educacional, os sujeitos constroem sistemas compostos por modelos e programas que os controlam para que eles funcionem de uma determinada forma.

A utilização da Robótica como recurso pedagógico de apoio ao ensino e à aprendizagem não é algo recente. O pioneiro desta atividade foi Saymour Papert, pesquisador do MIT (Instituto de Tecnologia de Massachusetts). Seus estudos acerca da Robótica na educação começaram nos anos sessenta, quando também cunhou o termo "Construcionismo" (PAPERT, 1994). Papert notou como o computador atraía as crianças e assim começou a pesquisar como esse potencial poderia ser utilizado para facilitar o processo de aprendizagem. Um de seus trabalhos mais conhecidos é a criação da linguagem de programação $L O G O$. Essa linguagem tinha como elemento principal uma tartaruga, que inicialmente era um robô móvel que se deslocava no chão, mas com o aprimoramento do monitor de vídeo passou a ser representado de forma virtual na interface de um programa.

Ainda que defendesse o amplo uso do computador para aprender, o foco de Papert estava nos processos mentais, e não na máquina em si. Dedicou-se, então, a criar uma linguagem de programação na qual as crianças "ensinavam" os computadores. Papert (1985) acreditava que a aprendizagem poderia ser potencializada com a inserção da lógica de programação nas aulas. Ele defendia que construir e programar eram atividades que podiam promover o desenvolvimento do senso crítico e a autonomia para testar diferentes possibilidades para a resolução de um problema. Nas palavras do autor:

E ao ensinar o computador a "pensar", a criança embarca numa exploração sobre a maneira como ela própria pensa. Pensar sobre modos de pensar faz a criança tornar-se um epistemólogo, uma experiência que poucos adultos tiveram (PAPERT, 1985, p. 35).

Com a colaboração teórica de Papert (1985),baseado em seus experimentos, o Laboratório de Mídias do Massachusetts Institute of Technology (MIT/EUA) firmou um convênio com a LEGO ${ }^{\circledR}$ Dacta. Então, foi desenvolvido o kit de Robótica Educacional LEGO ${ }^{\circledR}$ Mindstorms (FIGURA 1). Através do kit, a tartaruga virtual programável, idealizada por Papert, agora está fora da tela do computador e no formato criado pelo aluno. Ela pode ser construída com os blocos plásticos na forma de um carro, uma moto, um animal, ou qualquer outro protótipo imaginado pelos construtores e, em seguida, programada pela linguagem RoboLab ${ }^{\circledR}$ (FIGURA 1) inspirada no LOGO (CABRAL, 2011). 
Figura 1- Kit Lego Mindstorms EV3 e ambiente de programação
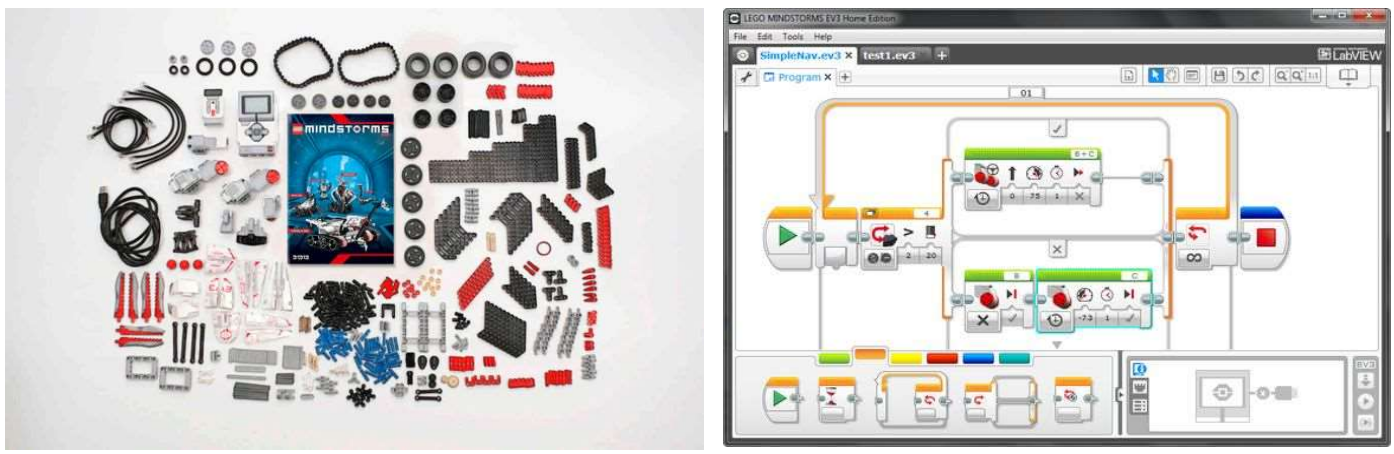

Fonte: Guia do usuário Lego Mindstorms EV3, 2018.

De acordo com Alzira (2009), os kits de Robótica Educacional podem ser instrumentos eficazes como mediadores dos processos de ensino e de aprendizagem. $\mathrm{O}$ robô, como elemento tecnológico, possui uma série de conceitos científicos cujos princípios básicos são abordados pela escola e mexem com o imaginário dos estudantes, criando novas formas de interação e exigindo uma nova maneira de lidar com símbolos. Dessa forma, a Robótica Educacional desenvolve um processo de motivação, colaboração, construção e reconstrução.

Diante dessas considerações, a Robótica educacional pode favorecer a aplicação dos pressupostos das Metodologias Ativas. As Metodologias Ativas estão fundamentadas na autonomia, um princípio significativo e libertador. Dessa forma, o ensinar exige respeito à dignidade de cada sujeito, levando em consideração que ele é responsável por construir a sua própria história. Com base nessa ideia, enquanto o método tradicional prioriza a transmissão de informações e tem sua centralidade na figura do docente, no método ativo, os estudantes ocupam o centro das ações educativas e o conhecimento é construído de forma colaborativa (DIESEL et al., 2017).

Alguns dos pressupostos das Metodologias Ativas envolvem colocar o aluno diante de problemas ou desafios que mobilizem o seu potencial intelectual enquanto estuda para compreendê-los e/ou superá-los. Nesse sentido, Berbel complementa, afirmando que:

Os estudantes necessitam de informações, mas são especialmente estimulados a trabalhar com elas, elaborá-las e reelaborá-las em função do que precisam responder ou equacionar. Nesse caminho, é possível que ocorra, gradativamente, o desenvolvimento do espírito científico, do pensamento crítico, do pensamento reflexivo, de valores éticos, entre outras conquistas dessa natureza, por meio da educação, nos diferentes níveis, contribuindo para o desenvolvimento da autonomia na formação do ser humano e de futuros profissionais (BERBEL, 2011, p. 34).

Como método ativo, Mitri et al. (2008) defendem que a Resolução de Problemas tem o propósito de envolver e estimular o aluno, pois diante do problema ele se detém, examina, reflete, relaciona a sua história e passa a ressignificar suas descobertas. Segundo os autores, quando o docente elabora situações desafiadoras, ele possibilita ao aluno o contato com as informações e a produção do conhecimento. Aprender por meio da Resolução de Problemas, portanto, é uma das possibilidades de envolvimento ativo dos alunos em seu próprio processo de formação.

Aliando os pressupostos das Metodologias Ativas e das Práticas Experimentais Investigativas, foram propostas atividades de Robótica, com características de um 
trabalho científico. Dessa forma, os alunos trabalharam, resolvendo um problema ou desafio. Utilizaram a experimentação como meio para aproximar os conceitos teóricos e suas percepções, promovendo discussões e possíveis aprendizagens.

\section{METODOLOGIA DO TRABALHO}

O presente artigo apresenta dados de uma pesquisa qualitativa, envolvendo um grupo de alunos que participaram de uma série de atividades investigativas com o apoio dos kits de Robótica da Lego Mindstorms, as quais foram promovidas para a introdução de alguns conceitos referente ao estudo da Física nas aulas de Ciências. Além disso, a pesquisa aproxima-se de alguns pressupostos teóricos do estudo de caso, pois buscou-se responder questões do tipo "como" e "por que" e o foco concentrou-se em fenômenos contemporâneos inseridos no contexto da vida real (YIN,2015, p.4).

A prática pedagógica foi realizada em uma escola pública da rede municipal, situada na cidade de Lajeado, RS. Participaram desta, vinte alunos do nono ano do Ensino Fundamental, com idade entre 13 a 16 anos: 13 anos (01 aluno), 14 anos (13 alunos); 15 anos (04 alunos) e com 16 anos (02 alunos). Foram realizados dez encontros com duração de duas horas cada, para o desenvolvimento das atividades propostas.

Durante o desenvolvimento dos trabalhos da intervenção pedagógica, foram utilizados os seguintes instrumentos para coleta de dados: questionários, exercícios sobre os temas da Física que foram desenvolvidos, relatórios produzidos pelos alunos, fotografias e gravações de áudio e de vídeos. Os questionários e exercícios tiveram o propósito de identificar os conhecimentos prévios que os alunos possuíam sobre os tópicos que foram abordados. Por meio dos relatórios elaborados e do questionário final foi possível analisar se as atividades apoiadas na Robótica contribuíram para o entendimento dos conceitos trabalhados, e se ocorreram possíveis aprendizagens.

Neste artigo apenas serão apresentadas e discutidas as atividades que envolviam o estudo dos conceitos de movimento e velocidade, em que os estudantes foram desafiados a realizar a montagem e a programação de um protótipo robótico. Para isso, os alunos formaram cinco equipes, e receberam um kit Lego Mimdstorns EV3 e um Notebook. Cada equipe foi organizada de forma que os alunos exercessem alternadamente, em cada encontro, as funções de construtor, organizador, programador e relator.

\section{ATIVIDADES DESENVOLVIDAS E DISCUSSÃO DOS RESULTADOS}

Para abordar os conceitos de movimento e velocidade num enfoque investigativo, baseado nos pressupostos da Resolução de Problemas, foram realizados diversos experimentos utilizando os protótipos robóticos construídos e programados pelas equipes. Concordando com Azevedo (2004), o objetivo dos experimentos não foi simplesmente comprovar uma teoria, mas mobilizar os alunos para a solução de um problema científico e, a partir daí, incentivá-los a procurar uma metodologia para chegar à solução do problema, bem como às implicações e às conclusões provenientes desse estudo.

Com base nessas concepções, as atividades práticas de Robótica Educacional foram conduzidas nos seguintes momentos:

- Fase inicial: os problemas foram expostos e discutidos; os alunos tiveram tempo para a elaboração de hipóteses e seleção de procedimentos instrumentais. De acordo com a situação problema elaborada, os alunos deveriam montar e programar um robô que seria utilizado no resgate de vítimas (FIGURA 2). Como forma de incentivar a participação e o envolvimento de todos os integrantes, foi proposto um desafio entre as equipes a fim de 
verificar qual delas conseguiria construir um robô que executasse o percurso no menor tempo possível.

Figura 2- Ilustração do desafio e equipes trabalhando na solução do problema
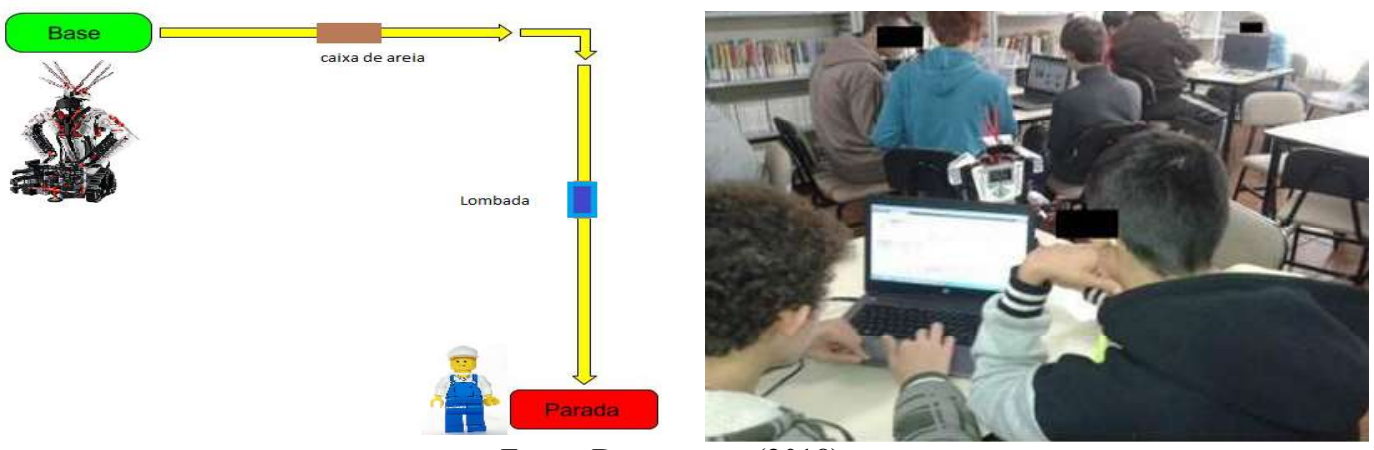

Fonte: Dos autores (2018).

- Fase de desenvolvimento: os experimentos foram realizados para coleta de dados. Nesse momento as equipes montaram os robôs e os prepararam para o desafio proposto. Os robôs de cada equipe foram submetidos a um experimento (FIGURA 3), a partir do qual foi possível coletar dados referentes ao movimento e velocidade.

Figura 3- Equipe realizando o experimento proposto

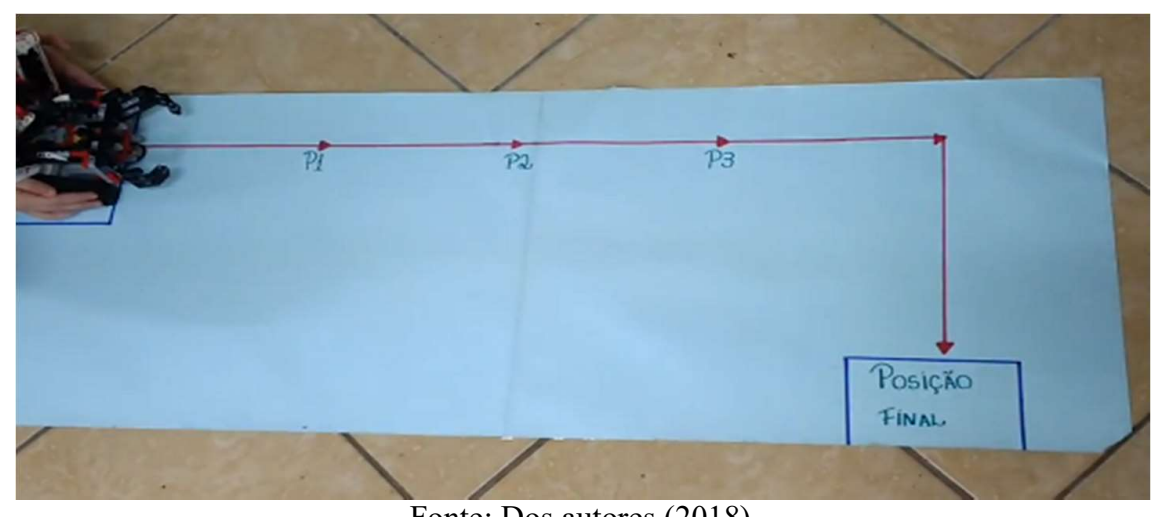

Fonte: Dos autores (2018).

- Fase de busca de referencial teórico e de reflexão: os alunos analisaram e interpretaram os dados coletados. Solicitei às equipes que elaborassem um gráfico com os dados coletados e apresentassem os cálculos com a previsão do tempo que o robô levaria para cumprir a missão estabelecida. Como referencial teórico, incentivei o uso do livro didático utilizado pela turma (BARROS; PAULINO, 2015), bem como outros livros que poderiam ser consultados em meio físico eletrônico.

- Fase de elaboração de um relatório: os alunos registraram as atividades desenvolvidas, bem como a análise e interpretação dos resultados obtidos.

Ao comparar o material produzido por meio do relatório, bem como as respostas do questionário final de avaliação das atividades de Robótica, com as respostas das questões aplicadas antes da intervenção, foi possível perceber uma evolução significativa na descrição dos conceitos sobre movimento. $\mathrm{O}$ quadro 1 a seguir apresenta a transcrição das respostas de alguns alunos, as quais evidenciam uma compreensão mais abrangente acerca do conceito estudado. 
Quadro 1 - Comparativo da descrição do conceito sobre movimento

\begin{tabular}{|c|c|c|}
\hline & Movimento (conceito inicial) & Movimento (conceito pós-intervenção) \\
\hline A-6 & Variação de posição de um objeto. & $\begin{array}{l}\text { Deslocamento de um corpo ou objeto em } \\
\text { relação ao seu referencial, num } \\
\text { determinado tempo. }\end{array}$ \\
\hline A-08 & $\begin{array}{l}\text { É um corpo que se desloca de um } \\
\text { ponto para outro. }\end{array}$ & $\begin{array}{l}\text { Mudança de posição de um objeto } \\
\text { ocasionada por uma força em relação ao } \\
\text { seu referencial. }\end{array}$ \\
\hline A-10 & $\begin{array}{l}\text { Deslocamento de um ponto para } \\
\text { outro }\end{array}$ & $\begin{array}{l}\text { O movimento é relativo, depende do ponto } \\
\text { de referência que você está usando e deve } \\
\text { ser medido entre um espaço de tempo. }\end{array}$ \\
\hline$A-15$ & $\begin{array}{l}\text { Deslocamento de um corpo ou } \\
\text { qualquer objeto. }\end{array}$ & $\begin{array}{l}\text { Ocorre um movimento quando um objeto } \\
\text { muda sua posição no espaço em relação ao } \\
\text { seu referencial no decorrer de um tempo. }\end{array}$ \\
\hline
\end{tabular}

Fonte: Dos autores (2018).

A partir desse quadro comparativo, é possível constatar uma evolução na concepção do conceito de movimento por parte desses alunos. Inicialmente as respostas mencionavam apenas o fator deslocamento, ou variação de posição. Após a realização dos experimentos e demais atividades investigativas, os alunos puderam complementar a construção do conceito, incluindo questões fundamentais para o estudo do movimento, tais como um sistema de referência, e o tempo de observação. Vale destacar a resposta de A-10, que consegue descrever que o conceito de movimento é relativo, concordando com a explicação de Hewitt:

Quando discutimos o movimento de algo, descrevemos o movimento em relação a alguma outra coisa. Se você caminha no corredor de um ônibus em movimento, sua rapidez em relação ao piso do ônibus provavelmente é diferente de sua rapidez relativa ao asfalto. Quando dizemos que um carro de corrida alcança uma rapidez de 300 quilômetros por hora, queremos dizer que tal rapidez é relativa à estrada. A menos que outra coisa seja dita, sempre que nos referirmos à rapidez com que se movem as coisas em nosso ambiente, estaremos supondo-a relativa à superfície da Terra. $\mathrm{O}$ movimento é relativo (PAUL HEWITT, 2015, p. 40).

Além de uma melhor compreensão sobre a relatividade e outros aspectos fundamentais aplicados ao estudo do movimento, conforme destacado pelo autor supracitado, foi possível notar também progressos na concepção do conceito de Velocidade (rapidez). O quadro 2 apresenta a transcrição das respostas de alguns alunos, nas quais é possível verificar a evolução acerca da compreensão desse conceito.

Quadro 2 - Comparativo da descrição do conceito de velocidade (rapidez)

\begin{tabular}{|c|c|c|}
\hline & Velocidade (conceito inicial) & Velocidade (conceito pós-intervenção) \\
\hline A-2 & $\begin{array}{l}\text { Deslocamento de um corpo a um } \\
\text { determinado intervalo de tempo. }\end{array}$ & $\begin{array}{l}\text { É a grandeza que define a rapidez de um } \\
\text { movimento, ou seja quanto ele se } \\
\text { movimentou dividido pelo tempo. }\end{array}$ \\
\hline A-5 & $\begin{array}{l}\text { É quanto um objeto se move em um } \\
\text { período de tempo. }\end{array}$ & $\begin{array}{l}\text { É uma indicação da rapidez do movimento, é } \\
\text { obtida dividindo a distância percorrida pelo } \\
\text { tempo gasto. }\end{array}$ \\
\hline
\end{tabular}




\begin{tabular}{|l|l|l|}
\hline A-11 & $\begin{array}{l}\text { A distância que um corpo percorreu } \\
\text { em um determinado tempo, ex. } \\
\text { 80km em uma hora. }\end{array}$ & $\begin{array}{l}\text { Entendi que para calcular a velocidade } \\
\text { preciso saber a força, direção e o sentido que } \\
\text { objeto está indo, e depois pegar a distância } \\
\text { e dividir pelo tempo. }\end{array}$ \\
\hline A-18 & $\begin{array}{l}\text { É quanto uma pessoa ou coisa } \\
\text { consegue se mover. }\end{array}$ & $\begin{array}{l}\text { Precisamos saber a distância percorrida e o } \\
\text { tempo que levou, daí dividimos a distância } \\
\text { pelo tempo para saber sua velocidade. }\end{array}$ \\
\hline
\end{tabular}

Fonte: Dos autores (2018).

As respostas fornecidas antes da intervenção revelaram que algumas concepções necessitavam apenas de reforço para que houvesse um entendimento mais amplo do conceito de velocidade. Mesmo em nível fundamental, é possível constatar que os alunos são capazes de compreender aspectos mais complexos acerca de uma grandeza. A-11, por exemplo, menciona sobre os vetores que devem ser considerados no cálculo de velocidade. Dessa forma, foi possível explicar por que o conceito de rapidez é mais apropriado ao referir-se a grandeza que desconsidera o sentido e direção (HEWITT, 2015).

Quanto às estratégias adotadas para reduzir o tempo previsto, três equipes sugeriram remover peças não essenciais do robô a fim de deixá-lo mais leve. Também mencionaram que as pilhas deveriam estar com sua capacidade máxima. Duas equipes citaram que poderia ser feita uma regulagem dos motores no ambiente de programação, deixando-os com a potência máxima. Além das sugestões já mencionadas, uma das equipes avaliou que se o sistema de esteira que movimenta o robô fosse trocado por quatro pneus, iria diminuir o atrito, o que resultaria numa melhor performance. Além das modificações no próprio robô, todas as equipes perceberam que o caminho de retorno à base poderia ser executado em linha reta (FIGURA 4), diminuindo assim o percurso total e, consequentemente, reduzindo o tempo.

Figura 4 - Solução apresentada pelas equipes

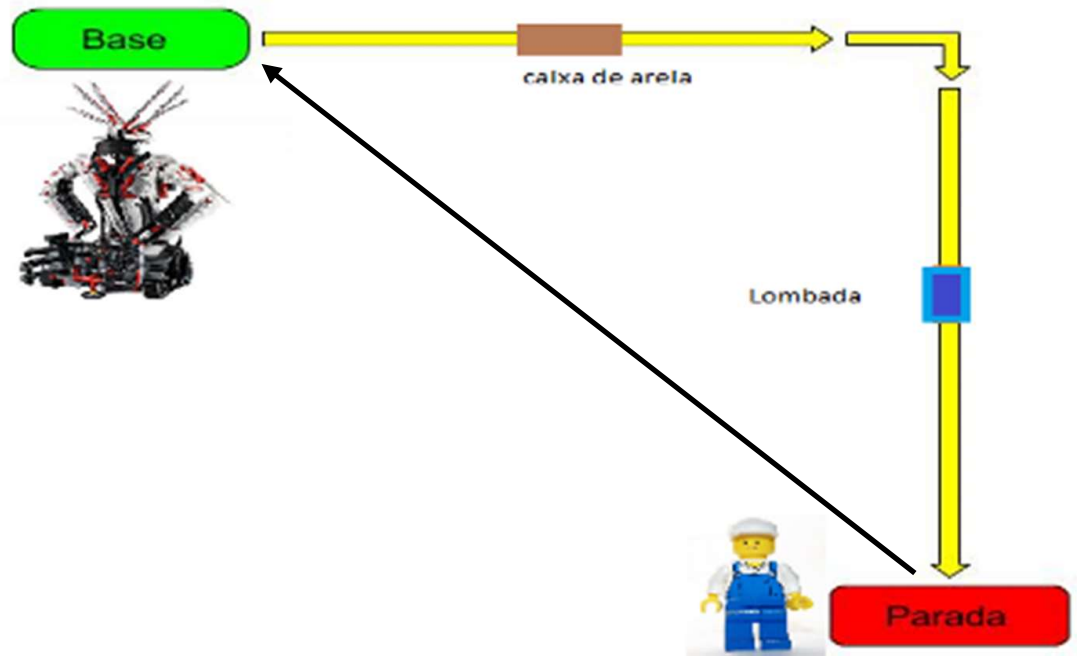

Fonte: Dos autores (2018).

Por meio da análise do material produzido, bem como dos procedimentos e sugestões apresentadas pelas equipes, ficou evidente possíveis aprendizagens, ou mesmo uma evolução nas concepções dos conceitos de movimento e velocidade. Além disso, os 
experimentos conduzidos num enfoque investigativo favoreceram uma participação ativa dos estudantes na construção de seu aprendizado. Portanto, as atividades de Robótica Educacional podem contribuir para uma mudança de atitude dos discentes, conforme destacado por Mitri et al:

O estudante precisa assumir um papel cada vez mais ativo, descondicionandose da atitude de mero receptor de conteúdo, buscando efetivamente conhecimentos relevantes aos problemas e aos objetivos da aprendizagem. Iniciativa criadora, curiosidade científica, espírito crítico-reflexivo, capacidade para auto-avaliação, cooperação para o trabalho em equipe, senso de responsabilidade, ética e sensibilidade na assistência são características fundamentais a serem desenvolvidas em seu perfil (MITRE et al. 2008, p.37).

O desenvolvimento dessas características foi favorecido pelas estratégias didáticas adotadas. As respostas fornecidas à questão do questionário final, que solicitava a descrição dos aspectos de que os estudantes mais gostaram nas atividades, revelaram que uma abordagem que propõe uma participação ativa torna o estudo mais atraente e significativo. Grande parte dos alunos (15 de 20) elencou a montagem e programação do robô, realizada pela equipe, e o experimento na pista de testes como as atividades de que mais gostaram.

\section{CONSIDERAÇÕES FINAIS}

A tecnologia atualmente está tão difundida e acessível, que tem resultado em novas formas de aprender, principalmente se levarmos em consideração as crianças e os adolescentes. As atividades realizadas demonstraram que a utilização de ferramentas tecnológicas inovadoras como a robótica, podem contribuir para despertar o interesse e aguçar a curiosidade dos estudantes, em especial, para abordar os conceitos de movimento e velocidade nos anos finais do Ensino Fundamental.

A Robótica Educacional pode proporcionar aos alunos uma forma diferenciada de visualizar a aplicabilidade dos conceitos da Física em situações reais de seu cotidiano. Pode levá-los a perceberem que, por meio estudo da Física, é possível entender e explicar diversos fenômenos e reações. Por meio da análise do material produzido, bem como dos procedimentos e argumentos apresentados pelos estudantes nessas atividades, foi possível evidenciar uma melhor compreensão, resultando em uma evolução dos conceitos de movimento e velocidade, quando comparado com suas concepções iniciais.

Ao aliar os pressupostos das Metodologias Ativas e de Práticas Experimentais Investigativas, com as atividades de robótica, foi possível desenvolver um trabalho científico. Dessa forma, os alunos trabalharam resolvendo um desafio, utilizando a experimentação como meio para aproximar os conceitos teóricos e suas percepções, promovendo discussões e possíveis aprendizagens. Além disso, as atividades de robótica favorecem a aplicação do método ativo de ensino, no qual os estudantes ocupam o centro das ações educativas e o conhecimento é construído de forma colaborativa (DIESEL et al., 2017).

Portanto, a aplicação dos princípios discutidos neste artigo, pode tornar o ensino dos conceitos da Física nos anos finais do Ensino Fundamental, mais interativo e dinâmico e permitir aos alunos uma participação ativa. Nessa concepção, os estudantes tornam-se protagonistas de seu aprendizado; não apenas entenderam o conteúdo abordado em aula, mas também conseguiram enxergar em quais momentos os conceitos de movimento e de velocidade são aplicados no cotidiano. 


\section{REFERÊNCIAS BIBLIOGRÁFICAS}

AZEVEDO, Maria Cristina P. Stella de. Ensino por investigação: problematizando as atividades em sala de aula. In: AZEVEDO, Maria Cristina P. Stella de. Ensino de Ciências-unindo a pesquisa e a prática. São Paulo: Cengage Learning, 2004. p. 19.

BARROS, Carlos; PAULINO, Wilson R. Ciências: física e química. São Paulo: Editora Ática, 2015. p. 35-36.

BERBEL, Neusi Aparecida Navas. As metodologias ativas e a promoção da autonomia de estudantes. Semina: Ciências Sociais e Humanas, v. 32, n. 1, p. 25-40, 2011.

BRASIL. Ministério da Educação e do Desporto. Base nacional comum curricular. Brasília. 2018. Disponível em:

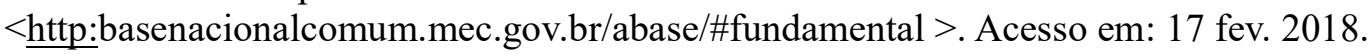

CABRAL, Cristiane Pelisolli. Robótica Educacional e Resolução de Problemas: uma abordagem microgenética da construção do conhecimento. Dissertação (Mestrado Profissional em Ensino de Física) - Instituto de Física, Universidade Federal do Rio Grande do Sul, Porto Alegre, 2011.

DIESEL, Aline; BALDEZ, Alda Leila Santos; MARTINS, Silvana Neumann. Os princípios das metodologias ativas de ensino: uma abordagem teórica. Revista Thema, v. 14, n. 1, p. 268-288, 2017.

FORNAZA, Roseli; WEBBER, Carine G. Robótica Educacional voltada ao Ensino de Física. Revista Novas Tecnologias na Educação, v. 12, n. 1, jul. 2014.

HEWITT, Paul G. Física Conceitual. 12. ed. Porto Alegre: Bookman, 2015.

MENEZES, Ebenezer Takuno de; SANTOS, Thais Helena dos. Verbete robótica educacional. Dicionário Interativo da Educação Brasileira - Educabrasil. São Paulo: Midiamix, 2015. Disponível em: $<\underline{\text { http: } / / \text { www.educabrasil.com.br/robotica- }}$ educacional/> . Acesso em: 08 dez. 2016.

MITRE, S. et al. Metodologias ativas de ensino-aprendizagem na formação profissional em saúde: debates atuais. Ciência e saúde coletiva, v. 13, supl. 2, 2008.

PAPERT, Seymor. A Máquina das Crianças: repensando a escola na era da informática. Porto Alegre: Artmed, 1994.

PAPERT, Seymour. Logo: Computadores e Educação. São Paulo: Brasiliense, 1985.

ROSATI, Mônica Neri. O lúdico aplicado no ensino aprendizagem e avaliação para o nono ano do ensino fundamental. 2015. Disponível em:

$<$ http://www.mnpef.unir.br/submenu_arquivos/2878_dissertacao_final_monica.pdf.>. Acesso em: 15 mar. 2018.

YIN, Robert K. Estudo de Caso: planejamento e métodos. São Paulo: Bookman, 2015. 